\title{
The distributions of trace elements (Fe, Mn, and REEs) in the East Sea (Japan Sea)
}

\author{
HOJONG SEO AND GUEBUEM KIM
}

Seoul National University

Presenting Author: seveneight93@snu.ac.kr

We present the data for $\mathrm{Fe}, \mathrm{Mn}$, and REEs from 28 depth profiles $(n=324)$ in the entire East Sea. In the East Sea, the vertical distribution patterns of these elements were similar to those in the major oceans. However, the concentrations of Fe, $\mathrm{Mn}$, and REEs in the surface layer $(0-50 \mathrm{~m})$ were 1.1-3.2, 1.44.3, and 1.2-3.0 fold higher than those in the North Atlantic Ocean, respectively. These higher concentrations were attributed to larger inputs from the atmosphere for Mn and REEs and from the continental shelf for Fe and $\mathrm{Mn}$. In this sea, the increase of REEs in the upper $750 \mathrm{~m}$ was proportional to the AOU (apparent oxygen utilization), while the increase from $750 \mathrm{~m}$ to bottom was independent of AOU. Therefore, we suggest that the distributions of REEs in the upper layer are associated with biological remineralization, and those in the deep ocean are associated with abiotic processes. The constant LREE to HREE ratios in this abiotic layer indicate re-scavenging of LREEs onto sinking particles. In the benthic boundary layer, we observed significant inputs of $\mathrm{Fe}$ and $\mathrm{Mn}$ from the bottom sediments, contrary to the boundary scavenging of REEs. Our results display comprehensive distribution patterns of trace elements in the East Sea, which reveal the boundary input and scavenging processes occurring in the productive areas of the ocean. 